\title{
Biocronoestratigrafia da Bacia de Pelotas: estado atual e aplicação na geologia do petróleo
}

\author{
Geise de Santana dos Anjos-Zerfass ${ }^{1}$, Paulo Alves de Souza ${ }^{2}$ \& Farid Chemale Jr. ${ }^{2}$
}

\begin{abstract}
Resumo Os estudos bioestratigráficos nas bacias sedimentares brasileiras têm fornecido suporte para a pesquisa exploratória de recursos minerais e energéticos, especialmente na margem continental. Com as descobertas de hidrocarbonetos nas bacias de Santos e Campos, a porção sul da margem continental brasileira tornou-se um importante alvo da exploração. Com isso, o refinamento bioestratigráfico se faz necessário para fins de detecção de hiatos e para o incremento da precisão das correlações laterais na delimitação e na análise espacial de possíveis reservatórios. O estado atual do arcabouço biocronoestratigráfico da Bacia de Pelotas é aqui apresentado, com vistas à sua aplicação na prospecção de reservatórios. Os principais problemas e lacunas no conhecimento acerca do tema são também discutidos. Em termos de bioestratigrafia, a bacia permanece pouco avaliada, apesar de que as pesquisas tenham começado em meados da década de 1960. A comparação entre propostas de biozoneamento para o Terciário da bacia permite inferir uma série de hiatos, de natureza até o momento desconhecida, identificados pela ausência de biozonas. Dois hiatos identificados a partir da curva de ${ }^{87} \mathrm{Sr}{ }^{86} \mathrm{Sr}$ elaborada para uma sondagem offshore, parecem estar relacionados com descontinuidades na deposição. As diferenças observadas entre os zoneamentos podem ser atribuídas aos diferentes critérios e níveis de resolução dos grupos taxonômicos utilizados, bem como aos diferentes intervalos amostrais empregados, o que afeta a resolução bioestratigráfica e, conseqüentemente, o potencial como ferramenta correlativa.
\end{abstract}

Palavras-chave: Micropaleontologia, Bioestratigrafia, Isótopos, Bacia de Pelotas.

\begin{abstract}
Biochronostratigraphy of the Pelotas Basin: Actual state and application in the petroleum geology The biostratigraphic studies of the Brazilian sedimentary basins have providing a support for the exploratory research of energetic and mineral resources, in particular at the continental margin. From new discoveries of hydrocarbon accumulations at the Santos and Campos basins, the south portion of the Brazilian continental margin were converted in an important target of the exploration. Therefore, the biostratigraphic refinement is necessary to detect gaps and to promote an increment on the precision of the lateral correlations in the delimitation and spatial analysis of the potential reservoirs. The actual stage of the bio-chronostratigraphic framework of the Pelotas Basin is presented herein, focusing on its application to the reservoir prospection. The main questions and lacunae on the knowledge are also discussed. In terms of biostratigraphy, the Pelotas Basin remains poorly evaluated, despite publication of important works on the biostratigraphy are known since the 1960's. A comparison of biostratigraphic schemes proposed for the Tertiary section of the basin allows the inference of diverse hiatuses, identified by the absences of biozones. Hiatuses identified in the ${ }^{87} \mathrm{Sr}{ }^{86} \mathrm{Sr}$ curve, suggest their relationship with discontinuities in the deposition. Discrepancies between the proposed schemes can be attributed to the particular resolution of the different groups used, the variations in the biostratigraphic criteria and the sampling interval, influencing the biostratigraphic resolution and therefore its potential as a correlation tool.
\end{abstract}

Keywords: Micropaleontology, Bioestratigraphy, Isotopes, Pelotas Basin.

INTRODUÇÃO Os estudos micropaleontológicos nas bacias sedimentares brasileiras, especialmente aquelas da margem continental, estão fortemente relacionados com a indústria do petróleo, de modo que o conhecimento acerca do tema evoluiu ao ritmo das atividades de exploração em cada bacia. O refinamento bioestratigráfico se faz necessário para fins de detecção de descontinuidades no registro estratigráfico bem como para promover o incremento da precisão nas correlações laterais, apoiando pesquisas que enfoquem a delimitação de possíveis reservatórios.

De modo geral, os microfósseis de parede calcária, silicosa ou orgânica constituem as ferramentas mais importantes para fins bioestratigráficos, dada a relativa abundância em amostras de testemunhos de sondagem e calha. Diversos grupos de microfósseis preenchem requisitos que os tornam ferramentas potencialmente úteis nas datações relativas e correlações a curtas e longas distâncias, além prover apoio nas interpretações paleoambientais. 
Com efeito, os distintos grupos de microfósseis têm sido extensivamente aplicados no estudo estratigráfico de praticamente todas as bacias da margem continental brasileira, tais como os nanofósseis calcários (Gomide 1982, Antunes 1987, Oliveira \& Costa 1997), foraminíferos (Abreu 1990, Mesquita 1995, Viviers \& Abreu 1995, Mello e Souza et al. 2003) e palinomorfos (Regali et al. 1974), além dos trabalhos nas bacias intracratônicas (Daemon \& Quadros 1970, Daemon \& Contreiras 1971, Altiner \& Savini 1995, Melo \& Loboziak 2003), como produtos vinculados aos diversos setores de pesquisa e exploração da Petrobras.

A Bacia de Pelotas encontra-se num estágio do conhecimento incipiente, com muito a ser aprofundado em termo de pesquisa quanto ao seu sistema petrolífero. Neste contexto, o estudo da sucessão microfossilífera se torna uma importante ferramenta nas atividades de exploração, mormente porque a bacia permanece pouco avaliada, embora os primeiros trabalhos bioestratigráficos datem de meados da década de 1960.

Os trabalhos mais modernos sobre o arcabouço estratigráfico da bacia utilizaram-se dos dados micropaleontológicos, especialmente de nanofósseis calcários (Gomide, 1989), como indicadores geocronológicos para o posicionamento das seqüências e das respectivas discordâncias (Dias et al. 1994, Fontana 1996). Além disso, os microfósseis também foram utilizados em reconstruções paleogeográficas, tais como aquelas esquematizadas com base em dinoflagelados por Arai (2007) para o Cretáceo da bacia, com aplicação no entendimento da evolução geológica de suas unidades e, indiretamente, dos padrões do comportamento tectono- estrutural ao longo de sua história.

Este trabalho objetiva discutir o significado geológico das associações microfossilíferas da Bacia de Pelotas e as implicações estratigráficas e paleogeográficas dos estudos realizados até o momento. Procura-se integrar as diversas propostas de arcabouço bioestratigráfico, na busca das principais descontinuidades na deposição, as quais podem estar relacionadas com discordâncias erosivas, importantes para a identificação de reservatórios. Discute-se também a aplicação de grupos taxonômicos que permitam uma maior detalhamento nas correlações entre as porções emersa e submersa da bacia, tais como os palinomorfos. Um primeira abordagem em termos de estratigrafia de isótopos de estrôncio é apresentada com o intuito demonstrar o potencial de refinamento oferecido por esta ferramenta. Com isto, busca-se apresentar os problemas e discutir perspectivas para futuras pesquisas de biocronoestratigrafia nesta porção da margem continental brasileira e sua potencialidade nos estudos exploratórios.

\section{CONSIDERAÇÕES GERAIS SOBRE A GEOLO-} GIA E PALEONTOLOGIA DA BACIA DE PELO-

TAS A Bacia de Pelotas corresponde ao trecho da margem continental sul-americana localizada entre os paralelos $28^{\circ} 40^{\prime} \mathrm{S}$ e $34^{\circ} \mathrm{S}$, sendo limitada ao norte pelo Alto de Florianópolis, e separada da Bacia del Este, ao sul, pelo Alto do Polônio, em águas territoriais uruguaias (Kowsmann et al. 1974, Rosa 2007) (Fig. 1). A bacia ocupa uma área de cerca de $210.000 \mathrm{~km}^{2}$ até a isóbata de $2.000 \mathrm{~m}$, dos quais cerca de $40.000 \mathrm{~km}^{2}$ de área emersa, constituem a Planície Costeira do Rio

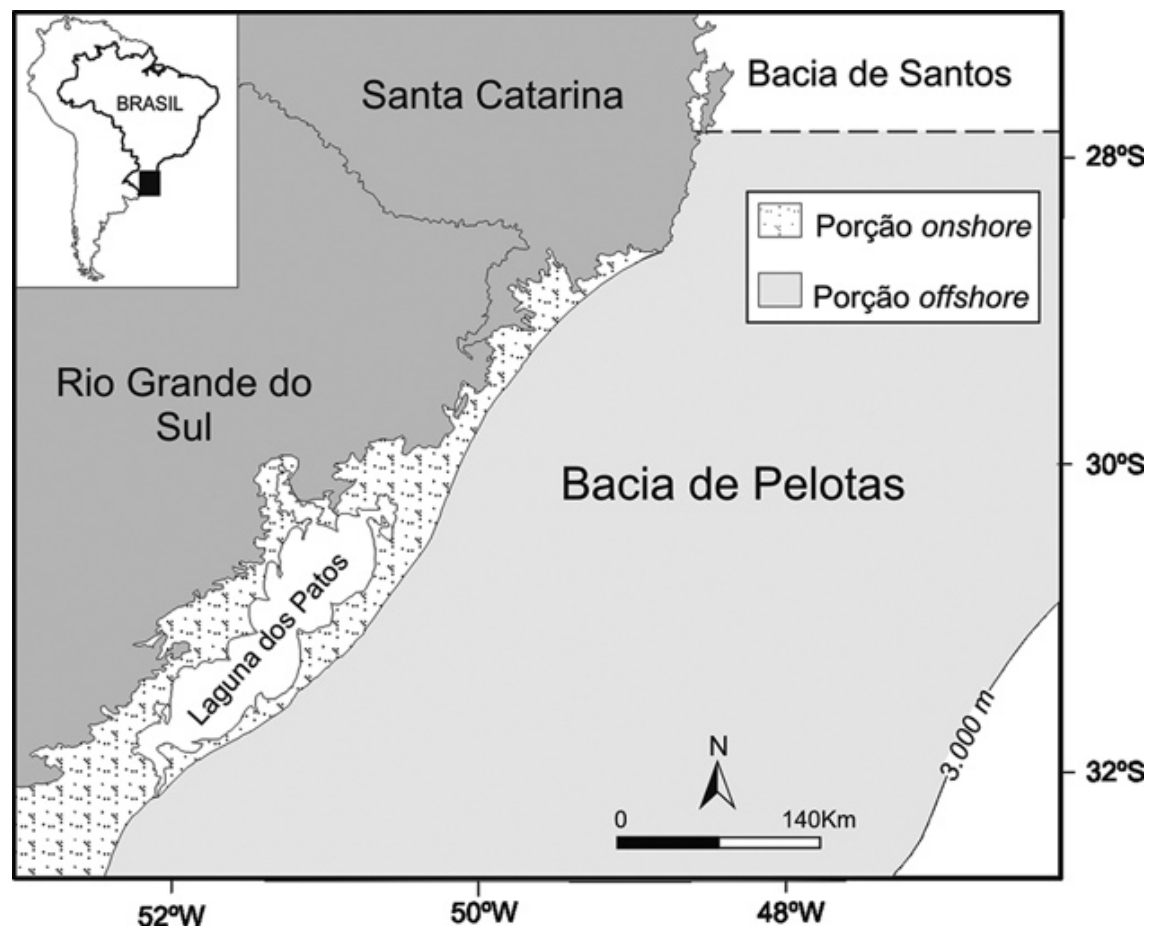

Figura 1 - Mapa de situação da porção brasileira da Bacia de Pelotas. 
Grande do Sul (Dias et al. 1994).

Na porção mais proximal, a bacia repousa sobre crosta continental e rochas basálticas extrudidas no início da fase rifte e, na sua porção mais distal, sobre o assoalho oceânico (Fontana 1990). Em crosta continental, seu embasamento corresponde a rochas do Escudo Sul-riograndense e Uruguaio e rochas paleozóicas e mesozóicas da Bacia do Paraná (Villwock \& Tomazelli, 1995).

Estruturalmente, a Bacia de Pelotas é considerada monótona. Nos depósitos da seção rifte, os estratos mergulham ligeiramente em direção ao oceano formando uma cunha que recobre o embasamento cortado por falhas antitéticas de grande rejeito que formam hemigrábens assimétricos, bem como falhas sintéticas e antitéticas de pequeno rejeito (Fontana 1987, Rosa 2007). A deformação da seção pós-rifte da bacia é incipiente, constituindo-se em exceções as estruturas de escorregamento associadas a falhas lístricas que afetam os depósitos pós-oligocênicos na região do Cone do Rio Grande (Fontana 1990, Chang et al. 1992).

A proposta litoestratigráfica mais atual para a bacia e cuja terminologia é amplamente aceita é aquela apresentada por Dias et al. (1994), que a subdividiram em nove unidades litoestratigráficas. De modo geral, predominam os depósitos clásticos e, subordinadamente, ocorrem rochas vulcânicas e calcarenitos. Apenas na região norte da bacia foi registrada a ocorrência de depósitos evaporíticos, os quais representam um pacote delgado de anidrita associado a carbonatos (Dias et al., 1994).

A Bacia de Pelotas é preenchida por depósitos sedimentares com idades que variam do Neocomiano ao Holoceno, sendo que na sua porção emersa, os depósitos mais antigos datam do eomioceno (Gomide 1989). Esta sucessão sedimentar foi subdividida por Fontana (1996) em 17 seqüências deposicionais. Segundo o autor, as seqüências depositadas entre o Neocomiano e o Eoceno têm caráter tectono-eustático, enquanto aquelas depositadas do Oligoceno ao Holoceno seriam glácio-eustáticas.

Os possíveis prospectos da Bacia de Pelotas são turbiditos cretácicos e terciários, especialmente aqueles de idade miocênica depositados no Cone do Rio Grande, onde foram verificadas fortes evidências da presença de hidratos de gás, além de ter sido comprovado o potencial para acumulação de gás (Fontana 1989, Sad et al. 1998, Deckelman et al. 2006, Rosa 2007). Estes depósitos apresentam características como a configuração, detectada através de seções sísmicas por Rosa (2007) e uma porosidade estimada por Deckelman et al. (2006) de 25 a $30 \%$, que os caracterizam como favoráveis ao acúmulo de hidrocarbonetos.

A seção quaternária da bacia engloba depósitos de leques aluviais e de quatro sistemas laguna-barreira, depositados nos últimos 400.000 anos em decorrência de eventos transgressivos de cunho glacio-eustático (Villwock \&Tomazelli 1995). Estudos concernentes ao conteúdo fossilífero dos depósitos quaternários na bacia registraram uma abundante associação de fósseis, englobando desde macrofósseis de vertebrados e invertebrados continentais e marinhos a microfósseis pertencentes a diversos grupos taxonômicos, dentre os quais diatomá- ceas, foraminíferos, nanofósseis, ostracodes, radiolários e palinomorfos marinhos e continentais, registrados em sondagens e em depósitos aflorantes (turfeiras, lagoas, lagunas e depósitos praiais). A análise destas associações fossilíferas tem sido aplicada com fins de caracterização paleoambiental e paleoclimática dos depósitos da Planície Costeira do Rio Grande do Sul.

Da mesma forma, os microfósseis têm fornecido o arcabouço bioestratigráfico para a seção pré-quaternária da bacia. Sucessões bioestratigráficas apoiadas em nanofósseis calcários, ostracodes, foraminíferos e em ocorrências ainda pontuais de palinomorfos (esporos, grãos de pólen, dinoflagelados, palinoforaminíferos) são apresentadas sinteticamente a seguir, na tentativa de ressaltar a contribuição desses grupos de microfósseis para o entendimento da evolução geológica da bacia.

\section{BIOESTRATIGRAFIA}

Fases de desenvolvimento As pesquisas micropaleontológicas realizadas na seção pré-quaternária da Bacia de Pelotas foram inteiramente baseadas em amostras de subsuperfície, uma vez que estes depósitos não afloram. No total, 19 sondagens forneceram as amostras utilizadas nos diversos estudos, sendo: oito poços perfurados pela Petrobras na porção emersa da bacia (2-CA-1-RS, 2-CI1-RS, 2-GA-1-RS, 2-GA-2-RS, 2-PN-1-RS, 2-PS-1-RS, 2-PJ-1-RS e 2-MO-1-RS); quatro sondagens efetuadas pela CPRM na porção emersa da bacia (TG-77, TG-99, TG-120 e TG-129); um poço perfurado pelo Instituto Geológico del Uruguay na porção emersa, (Chuy-364), e seis sondagens efetuadas pela Petrobras na porção submersa da bacia (1-SCS-2, 1-SCS-3B, 1-RSS-2, 1-RSS-3, 2-RSS-1 e 2-BPS-6A).

Até o momento não há a integração dos estudos bioestratigráficos envolvendo diferentes grupos taxonômicos para toda a bacia, apesar de trabalhos particularmente importantes com base em microfósseis terem sido desenvolvidos a partir da análise de amostras provenientes de poços perfurados pela Petrobras durante as décadas de 1970 e 1980.

As pesquisas estão concentradas na porção emersa da bacia e, de um modo geral, os esforços empreendidos no sentido de realizar o fatiamento bioestratigráfico da sucessão sedimentar da Bacia de Pelotas foram dirigidos principalmente para a seção pós-oligocênica, com raras exceções. Assim, podem ser definidas duas fases de desenvolvimento da pesquisa bioestratigráfica na Bacia de Pelotas. A primeira, uma fase de pesquisas na porção emersa, teve lugar nas décadas de 1960 e 1970. Os trabalhos realizados durante este período foram condicionados pela posição das perfurações e pelo tipo de microfauna presente nas amostras disponíveis. As sondagens efetuadas na época estavam localizadas exclusivamente na região da Planície Costeira do Rio Grande do Sul, onde os depósitos sedimentares mais antigos datam do eomioceno. Além desse aspecto, as amostras eram representativas de ambientes deposicionais transicionais, onde os microfósseis calcários planctônicos são escassos e as formas bentônicas não permitiram um bom refinamento bioestratigráfico. Vale 
ressaltar que os foraminíferos bentônicos não são os mais indicados para a elaboração de arcabouços bioestratigráficos uma vez que sua distribuição é fortemente controlada por variáveis ambientais. Entretanto, algumas exceções são registradas, dentre as quais os uvigerinídeos. As espécies deste grupo têm sido amplamente reconhecidos pela sua eficiência, tanto no refinamento de biozoneamentos efetuados com base em formas planctônicas, quanto na aplicação bioestratigráfica em seções onde os foraminíferos planctônicos estão ausentes, conforme assinalado por Lamb \& Miller (1984).

A segunda fase foi iniciada na década de 1980 , quando começou a publicação de estudos dos sedimentos da porção submersa da bacia, da plataforma continental, concomitantemente com o incremento das pesquisas realizadas na porção emersa. Nessa fase, o estudo de formas planctônicas, como foraminíferos e nanofósseis calcários, permitiu o fatiamento bioestratigráfico dos depósitos de toda a seção sedimentar da bacia, o que só começou a ser feito a partir dos anos 2000.

Principais propostas de fatiamento bioestratigráfico A seguir é apresentada uma síntese dos trabalhos que versam sobre a bioestratigrafia da bacia. Em vista da escassez de publicações de cunho estritamente bioestratigráfico, serão apresentados também os trabalhos que enfocam o posicionamento estratigráfico e a correlação dos estratos com base em microfósseis, ainda que não tenha sido proposta uma subdivisão dos conjuntos de estratos em biozonas. Os trabalhos de cunho bioestratigráfico realizados na bacia até o momento abordam a análise de associações de foraminíferos planctônicos, foraminíferos bentônicos, ostracodes, nanofósseis calcários e palinomorfos. Embora não tenham apresentado propostas de fatiamento bioestratigráfico para a sucessão sedimentar da bacia, os trabalho de Closs $(1966,1967)$, Boltovskoy et al. (1983), Madeira-Falcetta \& Thiesen (1988) com base na distribuição de foraminíferos planctônicos e de Kotzian \& Eilert (1985) com base na distribuição de ostracodes, forneceram informações para a correlação dos sedimentos do Mioceno-Pleistoceno.

A figura 2 mostra a distribuição dos trabalhos efetuados na seção pré-Quaternária da Bacia de Pelotas com base em diversos grupos de microfósseis.

FORAMINÍFEROS Em termos de foraminíferos bentônicos, três propostas de biozoneamentos informais foram apresentadas para a bacia. Closs (1970) propôs quatro zonas de associação informais para a seção miocênica dos oito poços perfurados pela Petrobras na bacia (Mio 1, Mio 2, Mio 3 e Mio 4). Através da calibração com base em foraminíferos planctônicos, estas biozo-

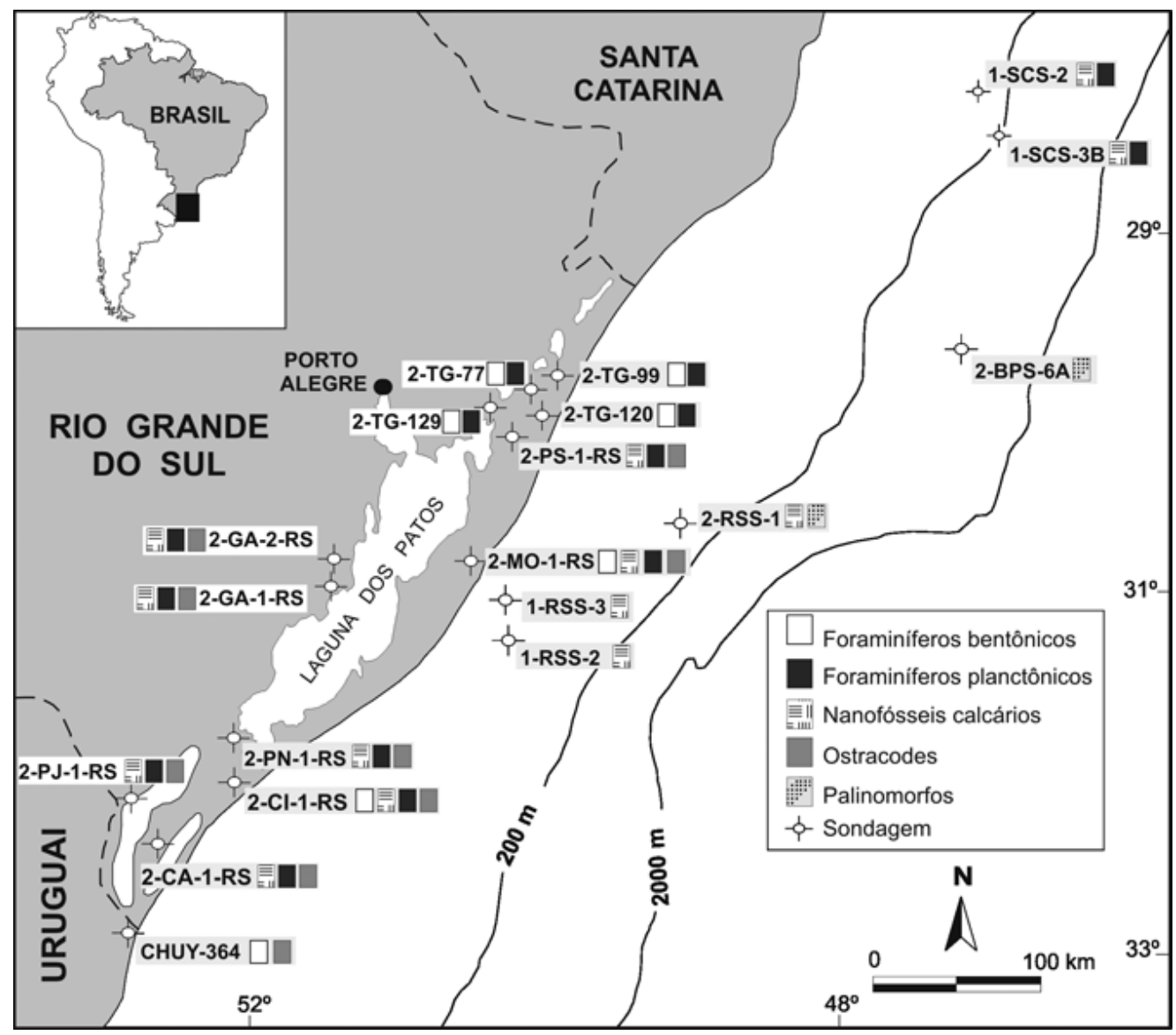

Figura 2 - Síntese dos estudos micropaleontológicos efetuados na seção pré-Quaternária da Bacia de Pelotas. 
nas foram posicionadas no limite entre as zonas formais de Bolli (1957) Globigerinatella insueta e Globorotalia fohsi fohsi, que corresponde indicam o intervalo entre o final eomioceno e o início do mesomioceno.

Posteriormente, Fernandes (1975) e Thiesen (1977) apresentaram propostas de biozoneamento para o mesomioceno e neomioceno das sondagens 2-CI-1RS e 2-MO-1-RS com base em foraminíferos bentônicos. Fernandes (1975) propôs quatro biozonas informais utilizando a distribuição vertical de espécies do gênero Uvigerina. A zona mais antiga proposta pela autora, Uvigerina gallowayi, foi individualizada pela ocorrência desta espécie e mais uma associação de 21 espécies e subespécies do gênero, a zona sobrejacente, Uvigerina hosiusi, foi caracterizada pela espécie que nomeia a zona e a ocorrência de três espécies restritas à zona ( $U$. altacostata, $U$. juncea e $U$. modeloensis) e uma associação de 21 espécies e subespécies. A zona Uvigerina acuminata foi caracterizada pelo aparecimento desta espécie, com um número elevado de exemplares, além da ocorrência de uma espécie restrita à zona - Uvigerina bermudezi - e mais uma associação de nove taxa. A zona Uvigerina subperegrina foi definida pela presença da espécie-índice, a qual é de ocorrência restrita a essa zona, associada a mais três espécies (U. calvertensis, $U$. laviculata e U. semiornata).

Thiesen (1977) sugeriu a subdivisão deste intervalo em três zonas informais baseadas na distribuição de associações de espécies do gênero Bolivina. A zona mais antiga, Bolovina anastomosa-Bolivina byramensis foi caracterizada pela abundância das espécies que nomeiam a zona e uma associação de espécies fortemente ornamentadas, a zona Bolivina beyrichi-Bolivina alata foi caracterizada pela abundância das espécies que nomeiam a zona e pelo desaparecimento das espécies ornamentadas que ocorrem na zona subjacente. A zona mais jovem, Bolivina regularis é caracterizada pela abundância desta espécie e pela diminuição do número de espécies do gênero Bolivina.

A figura 3 mostra a correlação entre as biozonas baseadas em foraminíferos bentônicos propostas pelos autores acima mencionados.

A partir do estudo das associações de foraminíferos planctônicos, duas propostas de biozoneamento fo-

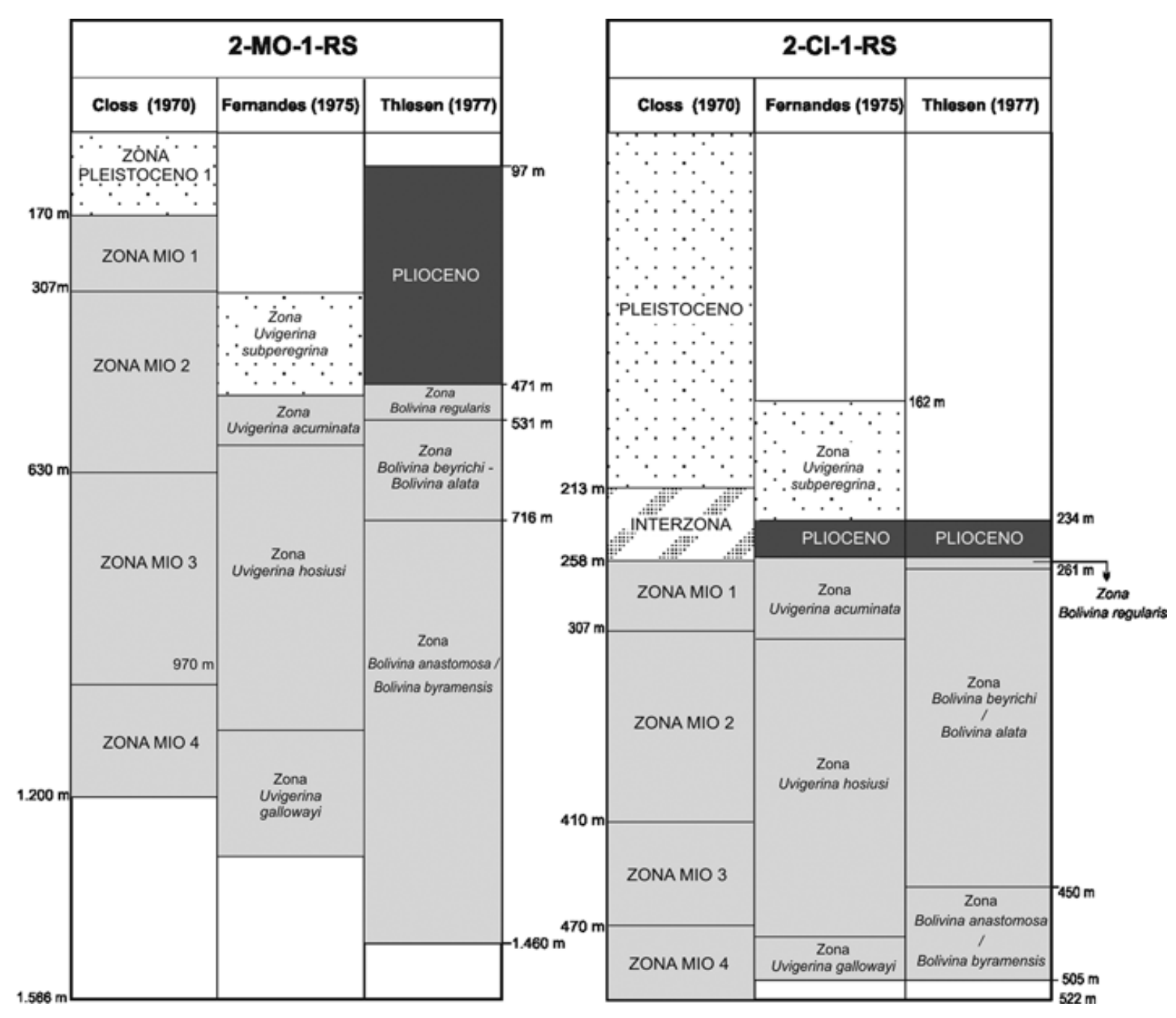

Figura 3 - Comparação entre as propostas de biozoneamento baseadas em foraminiferos bentônicos para os poços perfurados na porção emersa da Bacia de Pelotas. 
ram realizadas. A primeira foi apresentada por Koutsoukos (1982), que fez ainda a interpretação paleoambiental dos estratos perfurados pela sondagem 1-SCS-3B, na porção norte da bacia. O autor identificou 19 unidades descritas no arcabouço bioestratigráfico padrão de Noguti \& Santos (1972), idealizado para as bacias da margem costeira brasileira, além de uma zona informal para o Maastrichtiano, caracterizada pela ocorrência espécie bentônica Orthokarstenia spp. Posteriormente, Anjos (2004) abordou a seção Mioceno-Plioceno das sondagens 1-SCS-2 e 1-SCS-3B, tendo reconhecido sete biozonas e duas subzonas do esquema bioestratigráfico padrão para baixas latitudes de Bolli \& Saunders (1985).

Adicionalmente, estudo em andamento permite atribuir a idade eomioceno (parte terminal) ao testemunho do poço 2-RSS-1 coletado entre as profundidades de 1.300 e $1318 \mathrm{~m}$, com base na presença das espécies de foraminíferos planctônicos Catapsydrax dissimilis, Globigerinoides bisphericus, Globigerinatella insueta, Praerobulina transitoria e Praeorbulina glomerosa circularis. As espécies-índice estão ilustradas na figura 4.

OSTRACODES Três propostas de biozoneamento informal com base em ostracodes foram apresentadas para a Bacia de Pelotas. O zoneamento apresentado por Sanguinetti (1980) para a seção miocênica, amostrada em oito sondagens perfuradas pela Petrobras na porção emersa da bacia, é composto de três zonas e duas subzonas. A zona mais antiga proposta pela autora é a zona de amplitude local Bradleya rheingantzi, a qual foi caracterizada pelo prolongamento da ocorrência da espécieíndice a partir da base da zona sobrejacente (Bensonia midipunctata), ocorrido em apenas uma sondagem (2-MO-1-RS). A zona de B. midipunctata foi individua-

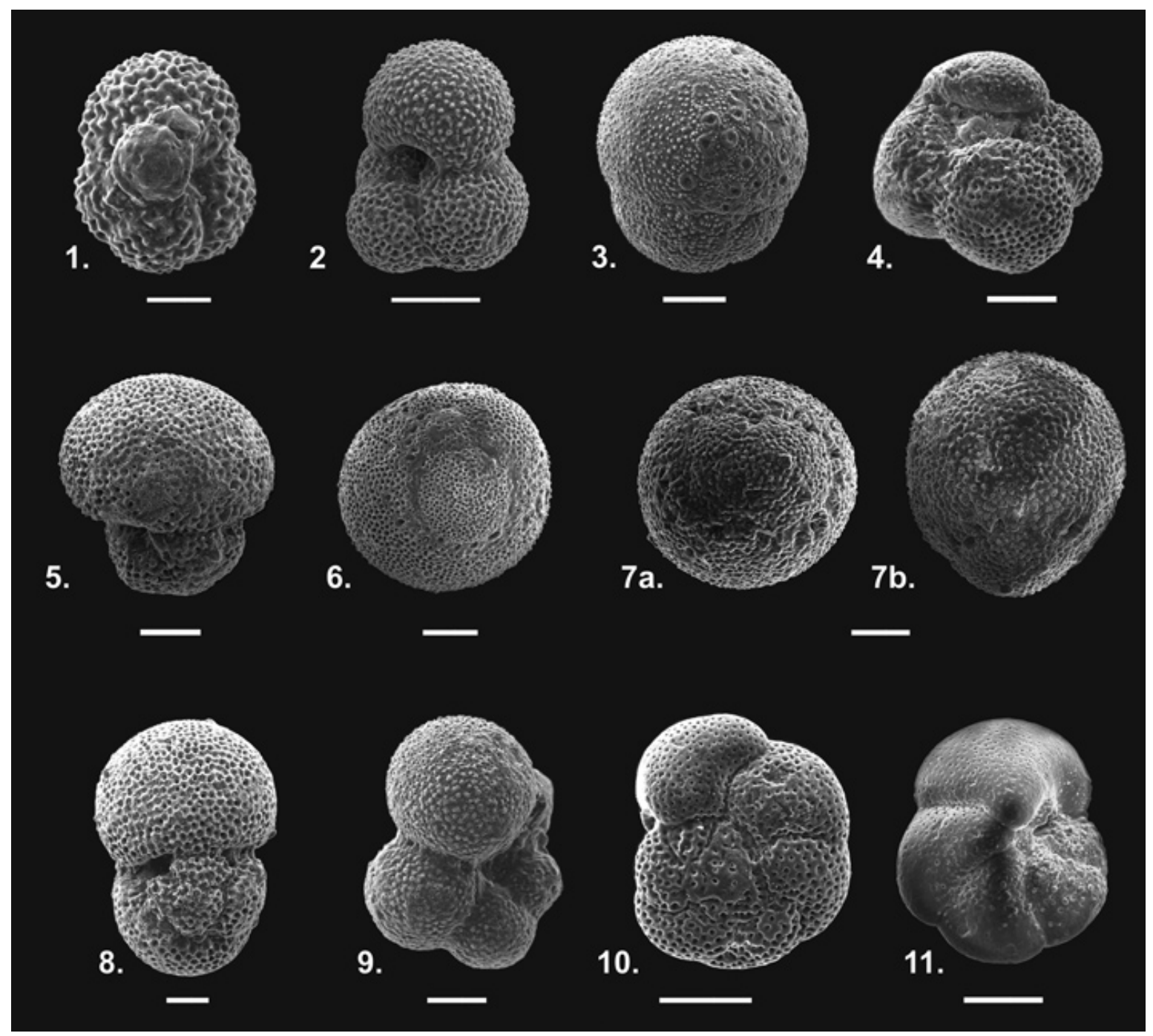

Figura 4 - Espécies-índice de foraminiferos planctônicos identificadas na sondagem 2-RSS-1. 1. Catapsydrax dissimilis (vista umbilical); 2. Globigerina praebulloides occlusa (vista umbilical); 3. Globigerinatella insueta; 4. Globigerina venezuelana; 5. Globigerinoides bisphericus; 6. Orbulina suturalis; $7 a, b$. Praeorbulina glomerosa circularis; 8. Praeorbulina transitoria; 9. Globorotalia obesa (vista umbilical); 10. Globorotalia fohsi peripheroronda. A escala corresponde a $100 \mu \mathrm{m}$. 
lizada pelo aparecimento da espécie que nomeia a zona, associada com Rocaleberis sylvesterbradleyi e Bradleya rheingantzi. A zona mais jovem, Henryhowella evax, é definida pela ocorrência da espécie-índice, além de $A u$ rila trigonula e Callistocythere litoralensis. Esta zona apresenta variações laterais da associação de espécies que permitem a individualização de duas subzonas $\mathrm{He}$ micytherura howei e Krithe trinidadensis.

Ornellas (1981) apresentou uma proposta de biozoneamento para a seção pós-miocênica em sete sondagens perfuradas na porção emersa da bacia. A autora propôs quatro zonas de associação, a mais antiga posicionada tentativamente no Plioceno, enquanto que às demais foi atribuída idade quaternária.

O trabalho de Carreño et al. (1997) apresenta um arcabouço bioestratigráfico para a seção neomicênicapleistocênica, a partir de sete poços perfurados na porção emersa da bacia (2-CA-1-RS, 2-CI-1RS, 2-GA-1-RS, 2-GA-2-RS, 2-MO-1-RS, 2-PJ-1-RS e 2-PN-1-RS). Os autores propuseram quatro zonas de associação e duas interzonas, em intervalos de baixa diversidade de espécies. Apenas uma das zonas propostas (Bradleya pelotensis) não está totalmente contida na seção quaternária, tendo sido posicionada tentativamente no intervalo entre o neomioceno e a porção inferior do Pleistoceno.

NANOFÓSSEIS CALCÁRIOS Gomide (1989) realizou o mais completo fatiamento bioestratigráfico da seção marinha da Bacia de Pelotas. O zoneamento foi realizado com base na distribuição vertical das associações de nanofósseis calcários recuperadas de sete sondagens efetuadas na porção emersa da bacia e cinco na porção submersa. $\mathrm{O}$ autor aplicou o esquema zonal de Troelsen \& Quadros (1971), modificado por Antunes (1984) e Shimabukuro et al. (1985). Os depósitos sedimentares da bacia foram divididos em 29 biozonas, sendo sete para o Cretáceo, duas para o Paleoceno, seis para o Eoceno, quatro para o Oligoceno, sete para o Mioceno e uma para o Quaternário (Pleistoceno). As biozonas têm caráter informal, mas sua operacionalidade é incontestável, apoiando trabalhos estratigráficos subseqüentes (Dias et al. 1994, Fontana 1996), conforme discutido nos itens que seguem.

PALINOMORFOS A contribuição de Regali et al. (1974), baseada na distribuição de grãos de pólen e esporos, constitui significativo marco para a bioestratigrafia da seção Cretáceo-Pleistoceno das bacias da margem costeira brasileira. Contudo, os autores não abordaram a Bacia de Pelotas. Para os poços onshore, o trabalho de Daemon (inédito) fornece significativo aporte bioestratigráfico a partir da análise do conteúdo palinológico da sucessão sedimentar perfurada por três sondagens, contudo trata-se de relatório interno da Petrobras, não publicado.

Após um longo período sem estudos palinológicos, a seção pré-quaternária da Bacia de Pelotas foi objeto duas comunicações, Arai et al. (2006) e Arai (2007), a última de caráter mais amplo, abordando cistos de dinoflagelados cretácicos de todas as bacias marginais brasileiras. Com base nesses microfósseis de parede orgânica, Arai (op. cit.) reconheceu barreiras físicas que restringiam a livre mistura de águas oceânicas entre o sul do Atlântico Sul e a porção norte, com fortes implicações no padrão de sedimentação da bacia.

Amostras de perfurações onshore e offshore da bacia constituem objeto de estudo de projetos específicos atualmente em andamento, com resultados preliminares do poço 2-RSS-1 apresentados em Premaor et al. (2007) e Fischer et al. (2007), relativos a intervalos do Cretáceo e do Paleoceno, respectivamente. A partir do estudo bioestratigráfico de palinomorfos, idades relativas estão sendo fornecidas, com significativa calibração com outros grupos de microfósseis, principalmente os nanofósseis calcários. Contribuições sobre a interpretação paleoambiental têm sido apresentadas, a partir do estudo da relação dos elementos marinhos (dinoflagelados, palinoforaminíferos) e continentais (esporos, grãos de pólen) presentes nas mesmas amostras, com implicações para o entendimento da dinâmica sedimentar, determinação e proximidade da área-fonte, natureza do transporte e eventos pós-deposicionais. Estas informações são imprescindíveis na reconstituição paleogeográficada bacia. Um estudo desta natureza foi realizado por Meyer et al. (2006) em material sub-recente da Planície Costeira do Rio Grande do Sul.

\section{SIGNIFICADO GEOLÓGICO DA SUCESSÃO MI-} CROPALEONTOLÓGICA Uma das implicações diretas do estudo das associações de microfósseis em uma bacia sedimentar é o detalhamento do arcabouço estratigráfico. A identificação de hiatos deposicionais, não detectáveis através de descontinuidades físicas, e o respectivo dimensionamento de suas amplitudes geocronológicas se constituem no principal avanço promovido pela bioestratigrafia em termos da compreensão das relações estratigráficas entre as diferentes unidades.

As biozonas são independentes das unidades lito- e cronoestratigráficas e seus limites são diácronos (NASC, 2005). Entretanto, a proximidade entre os limites zonais e os limites cronoestratigráficos, especialmente no caso da aplicação de microfósseis, permite atribuir idades com um alto grau de precisão a determinados depósitos. De acordo com Antunes \& Melo (2001), a bioestratigrafia torna possível a detecção de feições geológicas em escala de detalhe as quais dificilmente seriam visíveis em seções sísmicas.

A favorabilidade da prospecção de hidrocarbonetos é avaliada após a compreensão do modelo sedimentar da bacia, de modo que da análise de diversos fatores advêm os prognósticos sobre quais seções apresentam os possíveis reservatórios mais promissores.

A avaliação da duração e o correto posicionamento cronoestratigráfico dos hiatos, especialmente daqueles de caráter erosivo, desempenham um importante papel na prospecção de hidrocarbonetos. Além de constituírem, em diversos casos, trapas estratigráficas ou condutos para a migração de hidrocarbonetos, as discordâncias podem ser indicativas da ocorrência de depósitos turbidíticos nas porções mais profundas das bacias sedimentares (Shanmugan 1988, Richards et al. 
1998). Como são elementos geralmente formados durante quedas do nível relativo do mar, as discordâncias freqüentemente estão associadas à deposição de turbiditos na porção mais profunda das bacias sedimentares, depósitos estes associados ao leque de mar baixo (sensu Posamentier \& Vail 1988). Segundo Richards et al. (1998), os leques submarinos e outros depósitos marinhos profundos correlatos, contêm mais de $15 \%$ das reservas mundiais de petróleo em sistemas deposicionais predominantemente clásticos.

Os hiatos bioestratigráficos, entretanto, podem ser de natureza diversa da supressão de parte da seção por processos erosivos. Assim, ferramentas auxiliares são importantes para caracterizar os hiatos, como análise de fácies sedimentares, sismoestratigrafia, interpretação de perfis geofísicos e estudos isotópicos.

Para a sucessão sedimentar da Bacia de Pelotas, o emprego de diversos grupos taxonômicos para o fatiamento bioestratigráfico permitiu o reconhecimento de diversos hiatos, sendo que as divergências sobre o posicionamento das descontinuidades na sucessão micropaleontológica ocorreram devido a diferenças inerentes à resolução fornecida pelos distintos grupos taxonômicos e a variações nos intervalos amostrais.

As propostas bioestratigráficas mais abrangentes em termos de seção vertical (Koutsoukos 1982, Gomide 1989, Anjos 2004) resultaram da aplicação de esquemas zonais padrão de outras regiões mais setentrionais. Koutskoukos (1982) utilizou o esquema zonal para as bacias da margem continental brasileira de Noguti \& Santos (1972) com base em foraminíferos planctônicos. Gomide (1989) empregou o esquema zonal elaborado por Troelsen \& Quadros (1971) para as bacias da margem continental brasileira com base em nanofósseis calcários acrescido com as modificações de Antunes (1984) e Shimabukuro et al. (1985), enquanto Anjos (2004) aplicou o esquema zonal padrão de Bolli \& Saunders (1985) para regiões de baixas latitudes com base em foraminíferos planctônicos. Dessa forma, tornou-se possível posicionar os depósitos em termos geocronológicos, e constatar a presença de descontinuidades na sucessão bioestratigráfica através da ausência de biozonas. Isto levou à determinação de hiatos bioestratigráficos, os quais serão apresentados e discutidos nos próximos itens a partir de inferências realizadas com base em dados apresentados na literatura.

Cretáceo Apenas duas propostas de zoneamento bioestratigráfico para a seção cretácica foram efetuadas na Bacia de Pelotas, sendo que a mais abrangente corresponde a de Gomide (1989). Uma síntese das unidades bioestratigráficas, litoestratigráficas e seqüências deposicionais Bacia de Pelotas é apresentada na figura 5.

A idade mais antiga registrada corresponde ao Albiano/Cenomaniano, representada pela zona N-250 (Nannoconus truitti), a qual foi reconhecida por Gomide (1989) nas sondagens 1-SCS-2, 1-SCS-3B e 1-RSS-2. A zona N-255.2 (Corollithion aschylosum), que corresponde ao Turoniano, foi identificada apenas na porção mais setentrional da bacia, o que é um indicativo da existência de um hiato na porção sul da bacia entre o Albiano/Cenomaniano e o Turoniano.

O hiato de maior duração durante do Cretáceo foi identificado por Koutskoukos (1982), com a ausência do pacote sedimentar entre o Turoniano/Santoniano e o Albiano/Cenomaniano inferior, no poço 1-SCS-3B, em torno de $5 \mathrm{Ma}$. Este hiato não é sustentado pelos dados obtidos a partir do estudo das associações de foraminíferos, uma vez que o referido intervalo não apresentou formas diagnósticas. Este hiato apontado pelo autor provavelmente foi reconhecido a partir do biozoneamento por nanofósseis efetuado no âmbito da Petrobrás, à época da publicação.

Este hiato representa também uma importante descontinuidade paleoambiental com a deposição de carbonatos de ambientes rasos na seção subjacente à descontinuidade, e a deposição de pelitos na seção sobrejacente. $\mathrm{O}$ autor não relatou a ausência de biozonas, mas registrou a ausência de formas diagnósticas de parte da seção Santoniano-Albiano(?).Vale ressaltar que o estudo de Koutsoukos (1982) se baseou em apenas uma sondagem.

O Coniaciano/Santoniano está representado pela zona N-260 (Marthasteristes furcatus), a qual foi registrada em todas as sondagens offshore à exceção do poço 2-RSS-1, pois o mesmo não alcançou a profundidade prevista para os depósitos desta idade. A porção média do Campaniano foi bem registrado na bacia, tendo sido caracterizada pela zona N-265 (Eiffelithus eximius). A zona N-270 (Aspidolithus parcus constrictus), correspondente à porção superior do Campaniano e base do Maastrichtiano foi registrada apenas no poço 2-RSS-1. As zonas N-280 (Quadrum trifidum) e N-290 (Arkangelskiella cymbiformis) ocorreram em toda a bacia, e correspondem respectivamente às porções média e superior do Maastrichtiano. Um hiato com cerca de 2,9 Ma de duração foi identificado por Koutsoukos (1982) entre o Maastrichtiano e o Paleoceno na sondagem 1-SCS-3B.

\section{Cenozóico}

PALEOGENO A seção paleogênica da Bacia de Pelotas foi avaliada em termos de bioestratigrafia por Koutsoukos (1982) e Gomide (1989), tendo este último avaliado apenas a sondagem 1-SCS-3B, cotejando associações de foraminíferos planctônicos e nanofósseis calcários, respectivamente. A comparação entre o arcabouço bioestratigráfico, as unidades litoestratigráficas e as seqüências deposicionais para a seção paleogência da Bacia de Pelotas é apresentada na figura 6.

Com base nos dados de nanofósseis calcários obtidos por Gomide (1989), a zona N-350 (Fasciculithus spp.), que indica a porção superior do Paleoceno superior, não foi registrada nos poços 1-RSS-3 e 1-SCS-2, sendo que neste último também não foi encontrada qualquer outra zona do Paleoceno, que caracteriza um hiato, colocando os depósitos do Eoceno diretamente sobre os do Cretáceo na região da sondagem 1-SCS-2 (Fig. 8). A ocorrência de depósitos correspondentes à porção inferior/média do Paleoceno, representada pelas zonas N-320 (Cruciplacolithus tenuis) e N-340 (Heliolithus kleinpelli), segundo Gomide (op. cit.), é questionável 


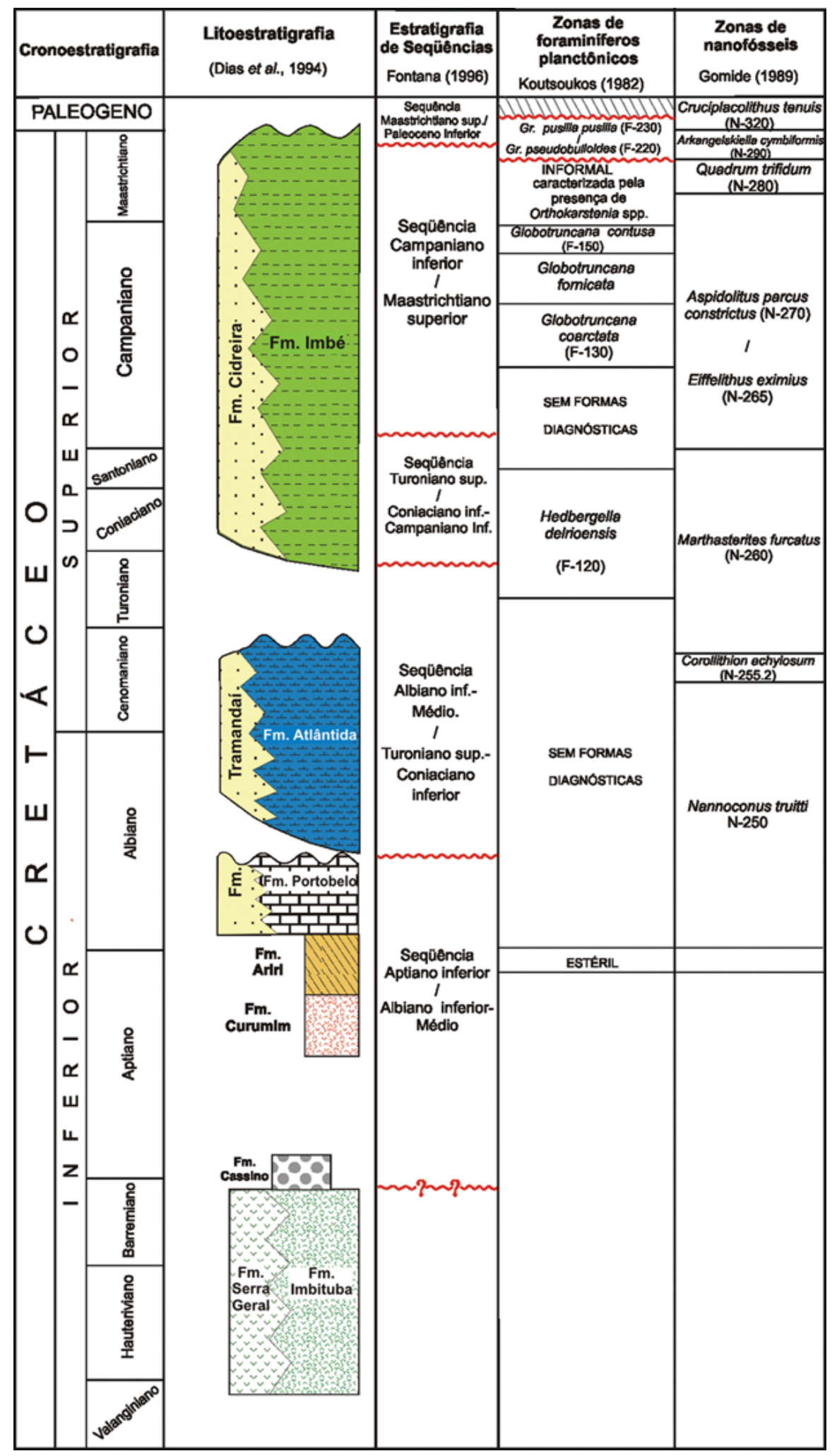

Figura 5 - Unidades bioestratigráficas, litoestratigráficas e seqüências deposicionais da seção cretácica da Bacia de Pelotas.

na bacia (Fig. 7). Segundo o autor, o intervalo correspondente ao Paleoceno aparentemente se adelgaça em direção ao norte e a mistura de fósseis do Paleoceno médio e inferior são um forte indicativo da ocorrência de um hiato importante.
Em termos de foraminíferos planctônicos, conforme a interpretação de Koutskoukos (1982) para a sondagem 1-SCS-3B, a seção paleocênica está representada apenas pela zona composta F-220/F-230 (Globorotalia pseudobulloides/Globorotalia pusilla pusilla) não tendo 


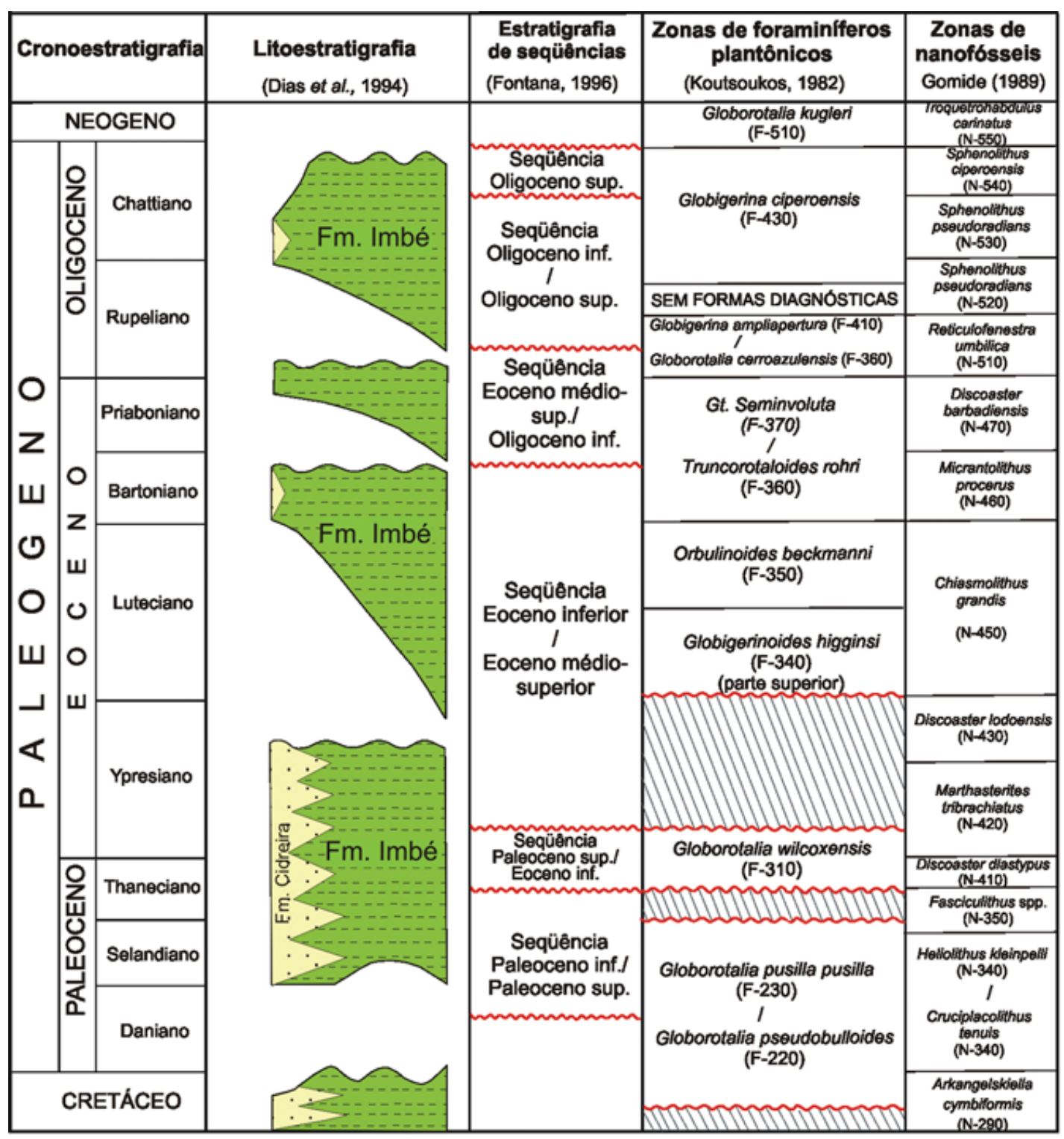

Figura 6 - Unidades litoestratigráficas, seqüências deposicionais e arcabouço bioestratigráfico para a seção paleogência da Bacia de Pelotas.

sido registradas as zonas F-210 (Globocontusa daubjergensis), que representa a porção inferior do Paleoceno inferior, e F-240 (Globorotalia peseudomenardii) e F-250 (Globorotalia velascoensis), que constituem a porção superior do Paleoceno superior (Fig. 6).

A ausência da zona N-410 (Discoaster diastypus), porção inferior do Eoceno inferior, não foi constatada nos poços 1-RSS-2 e 1-RSS-3, sugerindo um hiato entre o Paleoceno e o Eoceno na porção sul da bacia, enquanto que a zona N-420 (Marthasterites tribrachiatus), parte média do Eoceno inferior, não foi identificada nos poços 2-RSS-1, 1-SCS-2 e 1-SCS-3B, indicando um possível hiato na porção norte da bacia (Fig. 7). A zona N-430 (Diascoaster lodoensis), porção superior do Eoceno inferior ocorreu apenas nas sondagens 2-RSS-1 e 1-SCS-2.

Koutsoukos (1982) reportou a ocorrência de um hiato no poço 1-SCS-3B, marcando o limite entre o Paleoceno e o Eoceno inferior, cuja duração estimou em 3,5 Ma. Este hiato foi caracterizado pela ausência das zonas Globorotalia pseudomenrdii (F-240), Globorotalia velascoensis (F-250) e Globorotalia wilcoxensis (F-310) e também foi reconhecido nesta por Gomide (1989) nesta sondagem.

A zona N-520 (Sphenolithus pseudoradians), correspondente ao intervalo superior do Oligoceno inferior, ocorreu apenas no 1-RSS-3, o que denota a existência de um hiato na seção do eo-oligoceno. A zona N-470 (Discoaster barbadiensis), correspondente ao topo do Eoceno, não foi registrada nas sondagens 1-RSS-2 e 1-RSS-3, caracterizando um hiato entre o Eoceno e o Oligoceno.

Entre o Eoceno inferior e o Eoceno médio, Koutsoukos (1982) identificou a ausência das zonas F-320 (Globorotalia quetra) e F-330 (Globorotalia palmerae), bem como a ausência e da porção inferior da zona 


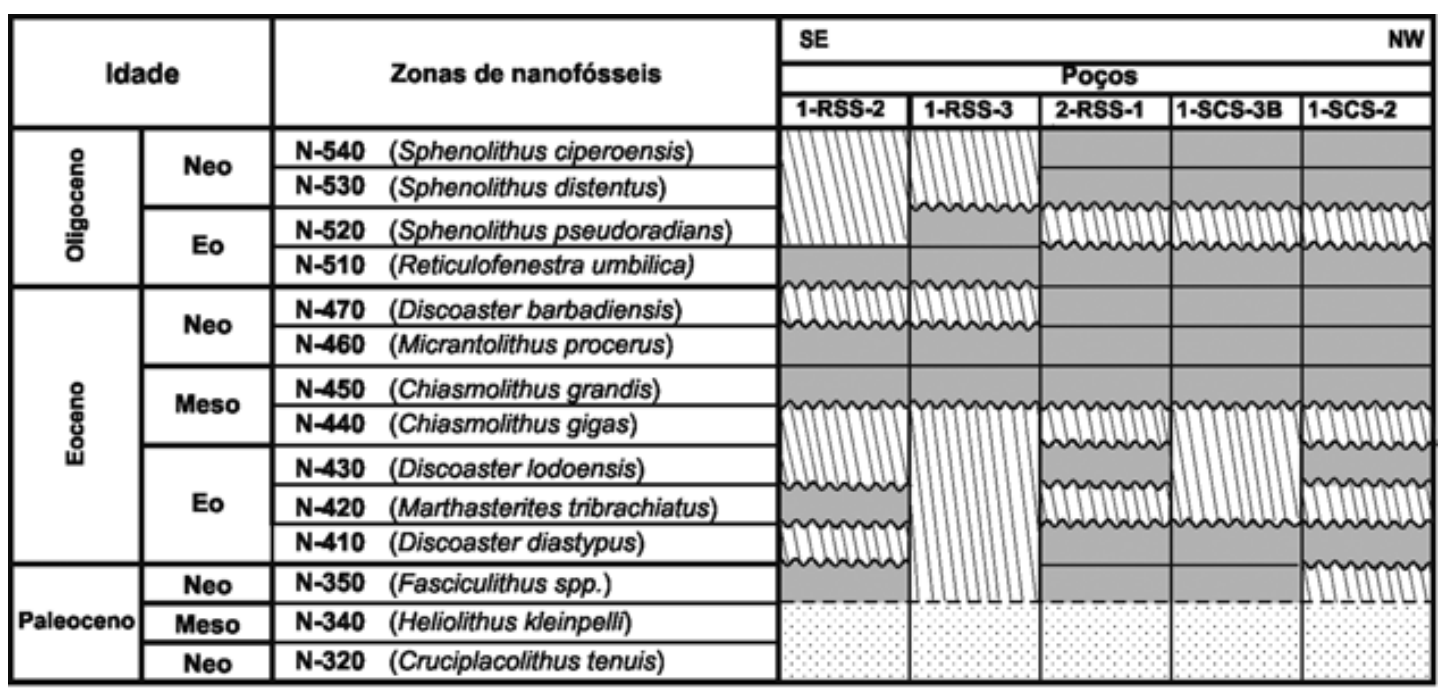

Legenda:

\section{Ocorrência \\ Ocorrência questionável

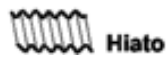

Figura 7 - Distribuição das biozonas de nanofósseis identificadas por Gomide (1989) para a seção do Paleogeno da Bacia de Pelotas.

F-340 (Globigerinoides higginsi) na seção perfurada pela sondagem 1-SCS-3B, o que interpretou como um hiato com duração estimada em 3,8 Ma. Digno de registro é o fato de que em todas as sondagens estudadas por Gomide (1989) identifica-se um hiato entre estratos do Eoceno inferior e médio, representado pela ausência da Zona N-440 (Chiasmolithus gigas) (Fig. 6).

Vale ressaltar que a correlação entre o topo da Zona F-430 (Globigerina ciperoensis ciperoensis), de Noguti \& Santos (1972), e o limite Oligoceno-Mioceno representa uma inconsistência, conforme apontado por Rios-Netto (1993), uma vez que o último aparecimento da espécie que nomeia a zona ocorreu no eomioceno. Assim, possivelmente o topo do Oligoceno estimado por Koutsoukos (1982) para a sondagem 1-SCS-3B esteja a uma maior profundidade na coluna sedimentar.

NEOGENO A seção neogênica da Bacia de Pelotas apresenta o arcabouço bioestratigráfico relativamente melhor detalhado, tendo sido avaliada em termos de foraminíferos planctônicos por Koutsoukos (1982) e Anjos (2004), e de nanofósseis calcários por Gomide (1989). As unidades litoestratigráficas, seqüências deposicionais e unidades bioestratigráficas que caracterizam a seção neogênica da bacia estão ilustradas na figura 8 .

A seção miocênica, segundo Gomide (1989), está completa nos poços perfurados na porção submersa da bacia. Entretanto, Koutskoukos (1982) e Anjos (2004), estes últimos com base apenas em poços perfurados na porção norte da bacia apontaram para a existência de vários hiatos na seção miocênica. Nos poços perfurados em terra, segundo os dados apresentados por Gomide (op. cit.), a Zona N-640 (Discoaster quinqueramus) foi identificada apenas no poço 2-MO-1-RS, caracterizando uma lacuna na sucessão das unidades bio- estratigráficas correspondente ao neomioceno. A Zona N-580 (Sphenolithus heteromorphus), porção inferior do mesomioceno, foi registrada apenas nas sondagens 2-GA-1-RS e 2-GA-2-RS, perfuradas na região de Graxaim, o que denota a existência de um hiato entre o mesomioceno e o eomioceno. A Zona N-590 (Cyclicargolithus floridanus), porção média do mesomioceno, foi registrada apenas no poço 2-MO-1-RS, caracterizando um hiato no mesomioceno (Fig. 9).

Entre o eomioceno e o mesomioceno, o autor registrou um hiato, correspondente à porção superior da zona F-520, Globigerina rohri (sensu Bolli, 1957), cuja duração foi estimada em 4,3 Ma (Fig. 8). Vale ressaltar que uma vez que a espécie-índice que nomeia a zona Globigerina rohri entrou em sinonímia com Globigerina tripartita Koch (1926), que se extinguiu no Oligoceno superior, de acordo com o alcance estratigráfico determinado por Bolli \& Saunders (1985). Assim, o posicionamento desta zona no eomioceno deve ser revisto.

Com base no esquema zonal de Bolli \& Saunders (1985), Anjos (2004) evidenciou a ausência de diversas biozonas na sucessão bioestratigráfica das sondagens 1-SCS-2 e 1-SCS-3B, sugerindo a presença de ao menos quatro hiatos, situados no limite OligocenoMioceno, eomioceno, limite eomioceno /mesomioceno e no limite Mioceno-Plioceno. Destes, apenas o hiato que marca o limite eomioceno -mesomioceno havia sido documentado previamente por Koutsoukos (1982) na sondagem 1-SCS-3B (Fig. 9).

Em relação ao biozoneamento com base em nanofósseis calcários, como as cartas de distribuição das espécies nos zoneamento para a margem continental brasileira não estão disponíveis, não é possível precisar se alguma das zonas internacionais está ausente. Entretanto, com base no esquema zonal de Perch-Nielsen 


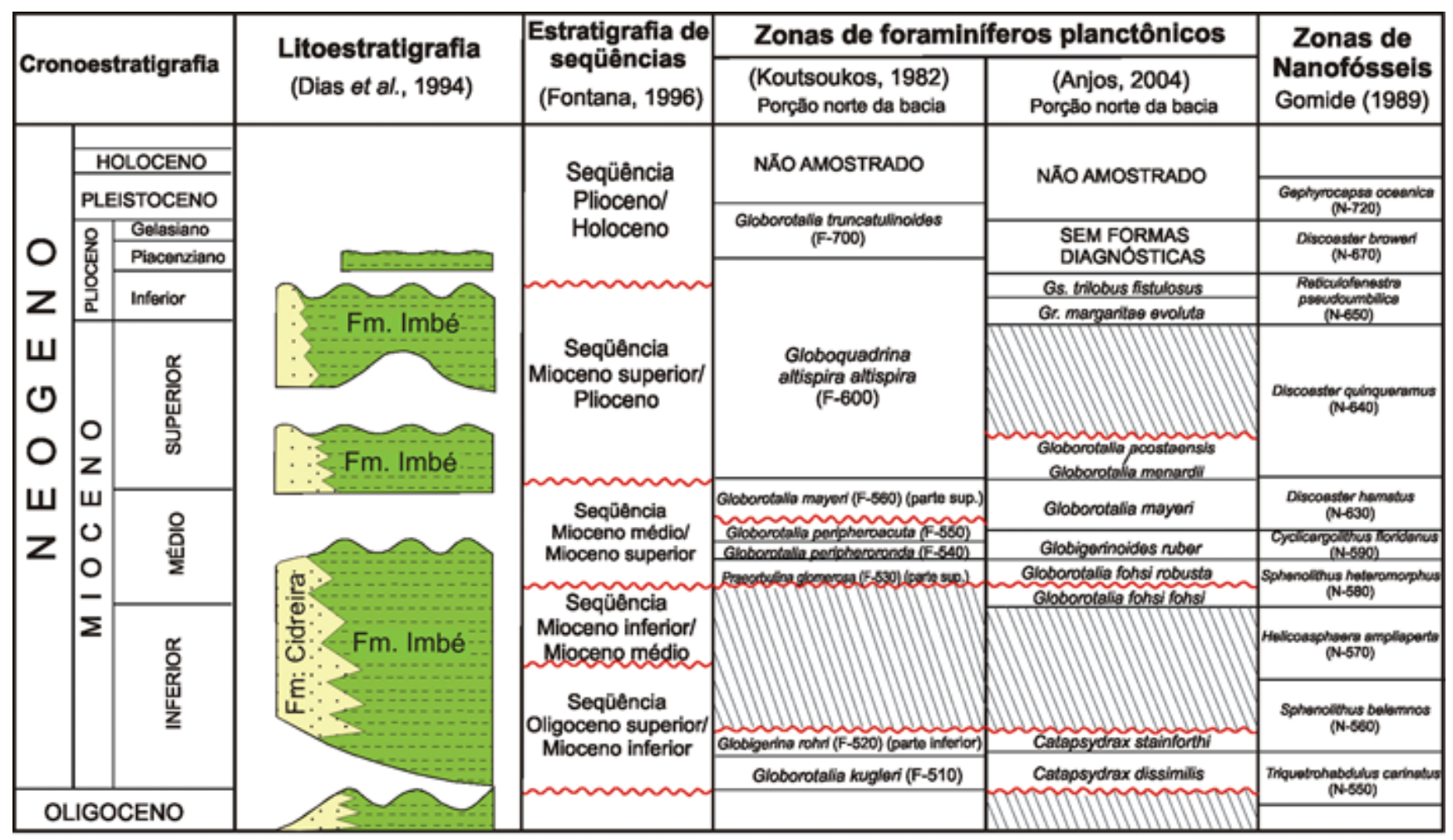

Figura 8 - Unidades litoestratigráficas, seqüências deposicionais e unidades bioestratigráficas da seção neogênica da Bacia de Pelotas.

\begin{tabular}{|c|c|c|c|c|c|c|c|c|c|c|}
\hline \multirow{3}{*}{\multicolumn{2}{|c|}{ Idade }} & \multirow{3}{*}{ Zonas de nanofósseis } & \multicolumn{8}{|l|}{ SE } \\
\hline & & & \multicolumn{8}{|c|}{ Poços } \\
\hline & & & 2-CA-1-RS & 2-PJ-1-RS & 2-Cl-1-RS & 2-GA-1-RS & 2-GA-2-RS & 2-MO-1-RS & 2-PS-1-RS & 2-PN-1-RS \\
\hline \multicolumn{2}{|c|}{ Pleistoceno } & N-720 (Gephyrocpsa oceanica) & & & & & & & & \\
\hline \multirow{2}{*}{ 施 } & Neo & N-670 (Discoaster browen) & & & & & & & & \\
\hline & Eo & $\mathrm{N}-650$ (Reticulofenestra psuedoumbilica) & & & & & & & & \\
\hline \multirow{5}{*}{ 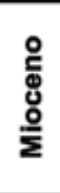 } & Neo & N-640 (Discoaster quinqueramus) & & & & & & & & \\
\hline & & N-630 (Discoaster hamatus) & & & & & & & & \\
\hline & Meso & N-590 (Cyclicargolithus floridanus) & & & & & & & & \\
\hline & & N-580 (Sphenolithus heteromorphus) & & & & & & & & \\
\hline & Eo & N-570 (Helicosphaera ampliaperta) & & & & & & & & \\
\hline
\end{tabular}

Legenda:

\section{Ocorrência Ocorrência questionável HIato}

Figura 9 - Distribuição das biozonas de nanofósseis reconhecidas por Gomide (1989) para a seção neogênica dos poços onshore da bacia de Pelotas.

(1985) para nanofósseis calcários e na avaliação da amplitude de várias espécies mencionadas no trabalho de Gomide (1989), aparentemente as zonas N-560 (Sphenolithus belemnos), N-630 (Discoaster hamatus), N-640 (Discoaster quinqueramus), N-650 (Reticulofenestra pseudoumbilica) de Gomide (1989), incluem duas ou mais zonas internacionais.

Assim, para a sondagem 1-SCS-2, entre as zonas N-590 (Cyclicargolithus floridanus) e N-630 (Discoaster hamatus), a ausência e/ou mistura de espécies caracte- rísticas de duas das zonas do esquema de Perch-Nielsen (1985) indicam uma forte correlação com o hiato reconhecido entre a zona Globorotalia mayeri e a subzona Globorotalia margaritae evoluta, ou seja, entre o mesomioceno e o eoplioceno. De modo similar, conforme observado por Anjos (2004) para a sondagem 1-SCS-3B, as zonas N-630 (Discoaster hamatus) e N-640 (Discoaster quinqueramus) de Gomide (1989) correspondem à zona indiferenciada Globorotalia acostaensis/Globorotalia menardii descrita pelas autoras supracitadas, a qual por 
sua vez corresponde ao hiato entre a zona mencionada e a subzona Globorotalia margaritae evoluta.

Através da aplicação do esquema zonal de Noguti \& Santos (1972), não é possível o detalhamento da seção do neomioceno - Plioceno uma vez que a zona F-600 (Globoquadrina altispira altispira) engloba desde a porção superior do mesomioceno até o limite entre o Plioceno e o Pleistoceno.

De acordo com Gomide (1989), a seção sedimentar do Plioceno está representada de forma completa nos poços perfurados na porção submersa da bacia, mas na porção emersa da bacia a zona N-650 (Reticulofenestra pseudoumbilica), que caracteriza o eoplioceno, não foi identificada nos poços 2-CA-1-RS, 2-PS-1 -RS e 2-PN-1-RS, enquanto a zona N-670 (Discoaster broweri), correspondente ao neoplioceno, foi registrada apenas na região do Baixo de Mostardas (sondagem 2-MO-1-RS) (Fig. 9).

ESTRATIGRAFIA DE ISÓTOPOS DE ESTRÔNCIO: CONTRIBUIÇÃO NO RECONHECIMENTO DE HIATOS Variações na razão ${ }^{87} \mathrm{Sr} /{ }^{86} \mathrm{Sr}$ da água do mar ao longo do tempo geológico têm sido utilizadas como ferramenta na correlação e datação relativa de sucessões sedimentares marinhas (Veizer et al. 1997). Em condições de preservação adequada, a razão isotópica da água do mar pode ser indicada a partir da análise de carapaças dos organismos marinhos. O acumulo de informações procedentes de diferentes seções bem preservadas e com bom controle cronoestratigráfico, de diferentes localidades no planeta, permitem a confecção de curvareferência para a evolução da razão de estrôncio dos mares ao longo do tempo geológicos. Assim é possível comparar e inferir idades relativas para uma seção estratigráfica objeto de investigação, a partir da similaridade com seção-referência (Farrell et al. 1995).

A curva isotópica de estrôncio de Chemale et al. (inédito) obtida a partir de análises de testas de foraminíferos provenientes de uma sondagem perfurada na porção offshore da Bacia de Pelotas representa uma primeira tentativa de ajuste cronoestratigráfico para a seção cenozóica da Bacia de Pelotas. As idades foram obtidas a partir da comparação das razões isotópicas de ${ }^{87} \mathrm{Sr} /{ }^{86} \mathrm{Sr}$ de Chemale et al. (inédito) com base na curva de referência de Koepnick et al. (1985) (Fig. 10). Com base nas idades relativas foi possível reconhecer dois hiatos, um entre o Eoceno médio e o Eoceno superior e outro entre o eo- e o neomioceno. Estas descontinuidades possivelmente estão associadas com discordâncias erosivas, tendo em vista a magnitude das mesmas. Por outro lado, hiatos de menor expressão podem não ter sido detectados na curva de estrôncio, o que pode ser atribuído à menor resolução da técnica em si ou ao intervalo de amostragem muito espaçado. (Fig. 10). Os resultados mostram que a estratigrafia de isótopos de estrôncio é uma ferramenta cronoestratigráfica robusta para a correlação e datação relativa de seqüências sedimentares marinhas, e atua como auxiliar no reconhecimento e/ou validação de hiatos significativos.

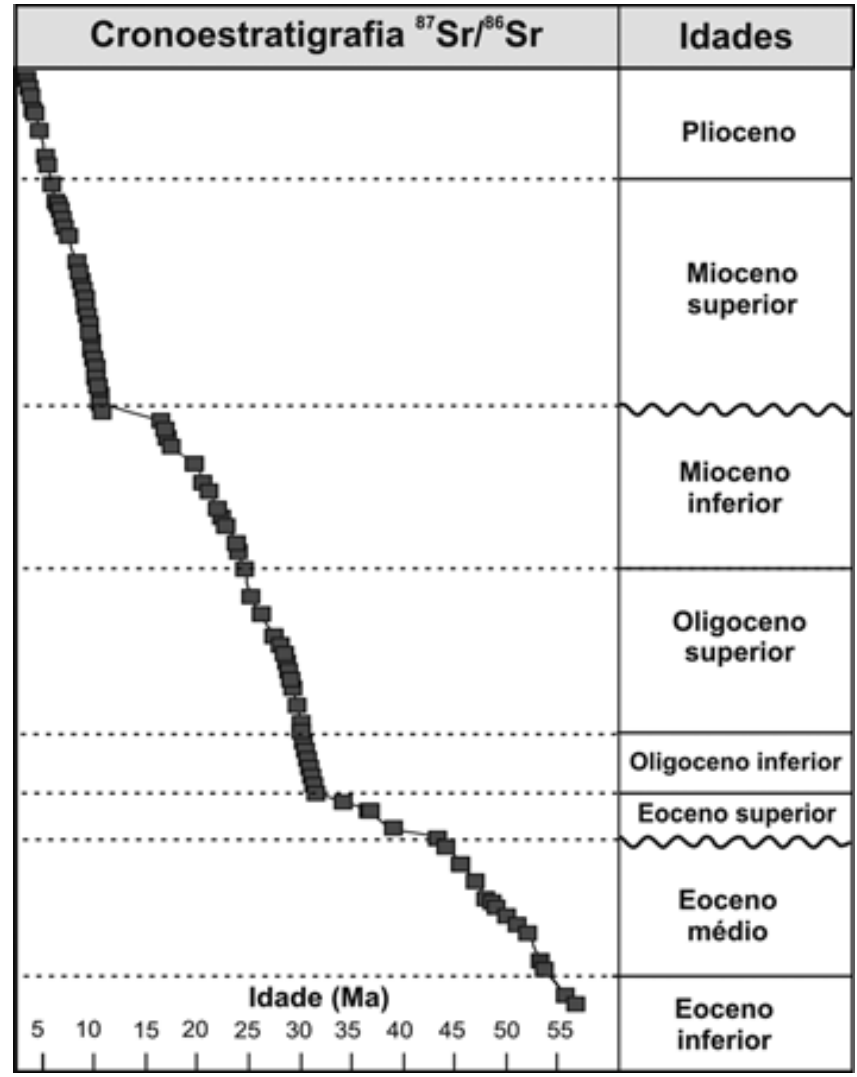

Figura 10 - Estratigrafia de isótopos de estrôncio para uma sondagem offshore da Bacia de Pelotas (modificado de Chemale inédito).

CONSIDERAÇÕES FINAIS As diferenças observadas entre os zoneamentos propostos para a Bacia de Pelotas podem ser atribuídas aos diferentes critérios e grupos taxonômicos utilizados pelos autores, bem como aos diferentes intervalos amostrais empregados, o que afeta diretamente a resolução bioestratigráfica.

A principal descontinuidade identificada através da bioestratigrafia é o hiato entre o Cenomaniano inferior/Albiano- Santoniano/Turoniano, reconhecido por Koutsoukos (1982) na sondagem 1-SCS-3B, o qual corresponde a uma mudança paleoambiental, passando de ambientes de plataforma rasa e ocasionalmente parálicos, a ambientes mais profundos.

Evidências baseadas nas associações de foraminíferos planctônicos e nanofósseis apontam para um hiato na sucessão paleocênica, com maior amplitude temporal na porção norte da bacia, e possivelmente de origem erosiva. Um hiato de menor magnitude que o anteriormente referido corresponde ao topo do Eoceno inferior, o qual não parece estar associado a uma mudança paleoambiental importante. No Eoceno médio, em sedimentos depositados em ambiente de plataforma rasa, a resolução bioestratigráfica foi reduzida, possivelmente devido ao pequeno potencial de preservação de microfósseis de parede calcária em ambientes de deposição rasos.

Na seção neogênica, até o momento a mais detalhada em termos de bioestratigrafia, várias descontinui- 
dades temporais foram reconhecidas na porção offshore da bacia com base no estudo dos foraminíferos planctônicos, as quais foram posicionadas na base do Mioceno inferior, entre o Mioceno inferior e médio, entre o Mioceno médio e superior e no limite Mioceno-Plioceno.

Dois hiatos reconhecidos a partir da curva isotópica de estrôncio, podem estar associados com discordâncias erosivas, importantes na prospecção de reservatórios de hidrocarbonetos. Assim, sugere-se que os estudos futuros busquem confirmar quais destas descontinuidades são de fato discordâncias erosivas. Isto pode ser realizado somando-se outras ferramentas exploratórias, tais como sismoestratigrafia, análise faciológica em testemunhos de sondagem e interpretação de perfis geofísicos. A micropaleontologia também pode constituir uma ferramenta nesta fase das pesquisas, auxiliando nas interpretações paleoambientais e paleobatimétricas, na busca de rápidos avanços dos sistemas mais proximais sobre os distais, característicos das desconformidades.

Em relação às propostas de zoneamento com base em foraminíferos planctônicos, em uma primeira avaliação, o esquema zonal padrão de Bolli \& Saunders (1985) parece oferecer uma resposta mais satisfatória, em termos de resolução na Bacia de Pelotas se comparado ao esquema formulado para as bacias da margem continental brasileira. Para o biozoneamento com base em nanofósseis calcários recomenda-se a aplicação de um esquema zonal de cunho internacional, amplamente divulgado na literatura, como o Perch-Nielsen (1985). Assim, sugere-se enfaticamente o estudo de detalhe à luz dos avanços desenvolvidos nas últimas décadas em termos taxonômicos, avaliando de modo criterioso a adequação do arcabouço bioestratigráfico proposto pelos autores supracitados à realidade da sucessão de bioeventos na Bacia de Pelotas.

Um problema a ser abordado em pesquisas futuras é o da baixa precisão das correlações entre a parte proximal e distal, onde a bioestratigrafia pode contribuir de forma efetiva. Tendo em consideração a escassez de formas planctônicas na porção onshore da bacia, conforme relatado por diversos autores, o biozoneamento com base em foraminíferos bentônicos apresentou resultados promissores, como observado nas tentativas de Fernandes (1975) e Thiesen (1977). Entretanto, recomenda-se também o fatiamento bioestratigráfico desta porção da bacia com base em palinomorfos e a caracterização das palinofácies, uma vez que os depósitos sedimentares desta região da bacia foram originados em ambientes rasos, propícios a serem hospedeiros de microfósseis de parede orgânica continentais, além dos organismos marinhos.

A caracterização das associações de foraminífe- ros bentônicos nos poços perfurados na porção emersa da bacia pode ser de grande valia no detalhamento paleoambiental dos depósitos, uma vez que a distribuição das biofácies destes organismos reflete características do ambiente deposicional dos sedimentos hospedeiros, tais como salinidade, nível de oxigenação e profundidade do corpo d'água. Associado à análise da distribuição dos foraminíferos bentônicos, a caracterização de palinofácies dos depósitos da porção emersa da bacia representa uma alternativa para seções onde a preservação dos microfósseis de parede calcária está comprometida por processos de dissolução.

Um problema a ser abordado em pesquisas futuras é o da baixa precisão das correlações entre a parte proximal e distal, onde a bioestratigrafia pode contribuir de forma efetiva. Tendo em consideração a escassez de formas planctônicas na porção onshore da bacia, conforme relatado por diversos autores, o biozoneamento com base em foraminíferos bentônicos apresentou resultados promissores, como observado nas tentativas de Fernandes (1975) e Thiesen (1977). Entretanto, recomenda-se também o fatiamento bioestratigráfico desta porção da bacia com base em palinomorfos e a caracterização das palinofácies, uma vez que os depósitos sedimentares desta região da bacia foram originados em ambientes rasos, propícios a serem hospedeiros de microfósseis de parede orgânica continentais, além dos organismos marinhos.

Para estudos futuros recomenda-se a aplicação da análise da razão isotópica ${ }^{87} \mathrm{Sr} /{ }^{86} \mathrm{Sr}$ em testas de foraminíferos, o pode corroborar o dimensionamento dos hiatos identificados através da bioestratigrafia, e fornecer idades relativas de depósitos onde microfósseis são escassos. Os estudos isotópicos da sucessão sedimentar da Bacia de Pelotas são preliminares, e ainda não publicados (Chemale et al., inédito), mostrando-se potenciais para a verificação e correlação dos hiatos detectados pelos métodos bioestratigráficos. A associação desses estudos com análises isotópicas de carbono e oxigênio e estratigrafia química, visando o reconhecimento de possíveis interferências nas determinações de idades por processos pós-deposicionais, também são aconselhados.

Agradecimentos Os autores agradecem ao Centro de Microscopia Eletrônica da UFRGS pela obtenção das fotomicrografias, a $\mathrm{H}$. Zerfass (CPRM) pela leitura crítica do texto, a RL Antunes e a um revisor anônimo pelas sugestões e questionamentos que muito contribuíram para a melhoria deste manuscrito.

GSAZ agradece ao PRH-12 pela infra-estrutura e a ANP pela bolsa de estudos. PAS e FCJ agradecem o auxílio do CNPq através de concessão de bolsas.

\section{Referências}

Abreu V.S. 1990. Bioestratigrafia do Terciário da Bacia de Campos, com base em foraminíferos planctônicos. Dissertação de Mestrado, Instituto de Geociências, Universidade Federal do Rio Grande do Sul, 235 p.

Altiner D. \& Savini R.R. 1995. Pennsylvanian foraminifera and biostratigraphy of the Amazonas and Solimões basins (north Brazil). Revue de Paleobiologie, 14:417-453.

Anjos G.S. 2004. Bioestratigrafia (Foraminiferida) do Mioceno-Plioceno da Plataforma de Florianópolis, porção setentrional da Bacia de Pelotas. Dissertação de Mes- 
trado, Instituto de Geociências, Universidade Federal do Rio Grande do Sul, 80 p.

Antunes R.L. 1987. Bioestratigrafia dos nanofósseis calcários do meso e neocretáceo da porca emersa da Bacia do Espírito Santo. Boletim de Geociências da Petrobrás, 1:3-11.

Antunes R.L. 1984. Geohistória do paleocanyon da Fazenda Cedro (Bacia do Espírito Santo) Segundo dados biocronoestratigráficos. In: SBG, Congresso Brasileiro de Geologia, 33, Anais, p. 670-684.

Antunes R.L. \& Melo J.H.G. 2001. Micropaleontologia e estratigrafia de seqüências. In: Ribeiro H.J.P.S. (Ed.). Estratigrafia de Sequências - fundamentos e aplicações. São Leopoldo, Editora Unisinos, p. 137-218.

Arai M., Masure E., Lemos V.B. 2006. Occurrence of a highdiversity Aptian microphytoplanktonic assemblage in Pelotas Basin (Southern Brazil): Its implication for the Early Cretaceous history of the South Atlantic. In: Simpósio do Cretáceo do Brasil, 7 e Simpósio do Terciário do Brasil, 1. Boletim, p. 12.

Arai M. 2007. Sucessão das associações de dinoflagelados (Protista, Pyrrophyta) ao longo das colunas estratigráficas do Cretáceo das bacias da margem continental brasileira: uma análise sob ponto de vista paleoceanográfico e paleobiogeográfico. Tese de Doutorado, Instituto de Geociências, Universidade Federal do Rio Grande do Sul, $170 \mathrm{p}$.

Bolli H.M. 1957. Planktonic foraminifera from the Oligocene-Miocene Cipero and Lengua formations of Trinidad, B.W.I. Bulletin of the United States National Museum, 215:97-123.

Bolli H.M. \& Saunders J.B. 1985. Oligocene to Holocene low latitude planktic foraminifera. In: Bolli H.M.; Saunders J.B., Perch-Nielsen K. (eds.). Plankton Stratigraphy. Cambridge, Cambridge University Press, p. 155-262.

Boltovskoy E., Thiesen Z.V., Madeira-Falcetta M. 1983. Foraminíferos de cuatro perforaciones de la planicie costera de Rio Grande do Sul (Brasil). Pesquisas, 15:127-149.

Carreño A.L., Coimbra J.C., Carmo D.A. 1997. Biostratigraphy of the Late Neogene and Quaternary ostracodes in the Pelotas Basin, Southern Brazil. Gaia, 14:33-43.

Chang H.K., Kowsmann R.O., Figueiredo A.M.F., Bender, A.A. 1992. Tectonics and stratigraphy of the east Brazil Rift System: An overview. Tectonophysics, 213:97-138.

Closs D. 1966. The presence and stratigraphical importance of the Orbulina surface in southern Brazil. Notas e Estudos da Escola de Geologia de Porto Alegre, 1(2):3-8.

Closs D. 1967. Miocene planktonic foraminifera from southern Brazil. Micropaleontology, 13(3):337-344.

Closs D. 1970. Estratigrafia da Bacia de Pelotas, Rio Grande do Sul. Iheringia (Série Geologia), 3:3-37.

Daemon R.F. \& Quadros L.P. 1970. Bioestratigrafia do Neopaleozóico da Bacia do Paraná. In: SBG, Congresso Brasileiro de Geologia, 24, Anais, p. 359-412.

Daemon R.F.\& Contreiras C.J.A. 1971. Zoneamento palinológico da Bacia do Amazonas. In: SBG, Congresso Brasileiro de Geologia, 25, Anais, p. 79-88.

Deckelman A., Lou S., D’onfro P.S., Lahann R.W. 2006. Quantitative assessment of regional siliciclastic top-seal potential: A new application of proven technology in the
Pelotas Basin, offshore Brazil. Journal of Petroleum Geology, 29(1):83-96.

Dias J.L., Silveira D.P., Sad A.R.E., Latgé M.A.L. 1994. Bacia de Pelotas: Estágio atual do conhecimento geológico. Boletim de Geociências da Petrobras, 8(1):235-245.

Farrell J.W.S., Clemens S., Gromet L.P., 1995. Improved chronostratigraphic reference curve of late Neogene seawater ${ }^{87} \mathrm{Sr} /{ }^{86} \mathrm{Sr}$. Geology, 23:403-406.

Fernandes J.M.G. 1975. O gênero Uvigerina (Foraminiferida) do Cenozóico superior na Bacia de Pelotas, Rio Grande do Sul, Brasil. Dissertação de Mestrado, Instituto de Geociências, Universidade Federal do Rio Grande do Sul, $121 \mathrm{p}$.

Fischer T.V., Premaor E., Arai M., Souza P.A. 2007. Palinologia da Bacia de Pelotas: Dados preliminares sobre a seção paleocênica. In: SBP, Congresso Brasileiro de Paleontologia, 20, Anais, p. 232.

Fontana R.L. 1987. Desenvolvimento termomecânico da Bacia de Pelotas e parte sul da Plataforma de Florianópolis. Dissertação de Mestrado, Instituto de Geociências, Universidade Federal de Ouro Preto, 128p.

Fontana, R.L. 1989. Evidências geofísicas da presença de hidratos de gás na bacia de Pelotas, Brasil. In: SBGf, Congresso Brasileiro de Geofísica, 1, Revista Brasileira de Geofísica, 7(1):93.

Fontana R.L. 1990. Investigações geofísicas preliminares sobre o Cone do Rio Grande, Bacia de Pelotas, Brasil. Acta Geológica Leopoldensia, 13(6):161-170.

Fontana R.L. 1996. Geotectônica e sismoestratigrafia da Bacia de Pelotas e Plataforma de Florianópolis. Tese de Doutoramento, Universidade Federal do Rio Grande do Sul, 214 p.

Gomide J. 1982. Bioestratigrafia no nanoplâncton calcário da bacia de Campos. Boletim de Geociências da Petrobrás, 25:129-137.

Gomide J. 1989. Bacia de Pelotas - Biocronoestratigrafia baseada em nanofósseis calcários. In: SBP, Congresso Brasileiro de Paleontologia, 11, Anais, p. 338-351.

Koepnick R.B., Burke W.H., Denison R.E., Hetherington E.A., Nelson H.F., Otto J.B., Waite L.E. 1985. Construction of the seawater [87] $\mathrm{Sr} /[86] \mathrm{Sr}$ curve for the Cenozoic and Cretaceous: Supporting data. Chemical Geology, 58(1-2):55-81.

Kotzian S.B. \& Eilert V.P. 1985. Ostracodes mio-pleistocênicos da perfuração Chuy n. 364, Bacia de Pelotas, Uruguai. Acta Geologica Leopoldensia, 20:81-94.

Kowsmann R.O. Francisconi O., Leyden R. 1974. Refração sísmica marinha nas bacias de Pelotas, Santos Sul e na Plataforma de Torres. In: SBG, Congresso Brasileiro de Geologia, 28, Anais, p. 283-295.

Koutsoukos E.A.M. 1982. Geohistória e paleoecologia das bacias marginais de Florianópolis e Santos. In: SBG, Congresso Brasileiro de Geologia, 32, Anais, p. 23692382.

Lamb J.L. \& Miller T.H. 1984. Stratigraphic significance of Uvigerinid foraminifers in the western hemisphere. The University of Kansas Paleontological Contributions, 66:1-99.

Madeira-Falcetta M. \& Thiesen Z.V. 1988. Foraminíferos da perfuração 2-GAst-1A-RS, Bacia de Pelotas. Pesquisas, 
21:49-59.

Melo J.H.G. \& Loboziak S. 2003. Devonian-Early Carboniferous miospore biostratigraphy of the Amazon Basin, Northern Brazil. Review of Palaeobotany and Palynology, 124:131-202.

Mello e Sousa S.H., Fairchild T.R., Tibana P. 2003. Cenozoic biostratigraphy of larger foraminifera from the Foz do Amazonas Basin, Brazil. Micropaleontology, 49(3):253266.

Mesquita A.C.F. 1995. Microbioestratigrafia do Terciário da bacia de Santos, com base em foraminíferos planctônicos. Dissertação de Mestrado, Instituto de Geociências, Universidade Federal do Rio Grande do Sul, 167 p.

Meyer K.E.B., Souza P.A., Cwik M.R., Menezes T.R., Buchmann F.S. 2006. Palinofácies e processos deposicionais em sedimentos de fundo da Lagoa dos Quadros, Planície Costeira do Rio Grande do Sul, Brasil. Revista Brasileira de Geociencias, 36(4):613-622.

NORTH AMERICAN COMMISSION ON STRATIGRAPHIC NOMENCLATURE (NACSN). 2005. North American Stratigraphic Code. American Association of Petroleum Geologists Bulletin, 89(11):1547-1591.

Noguti I. \& Santos J.F. 1972. Zoneamento preliminar por foraminíferos planctônicos do Aptiano ao Mioceno na plataforma continental do Brasil. Boletim Técnico da Petrobras, 15(3):265-283.

Oliveira L.C.V. \& Costa S.O. 1997. Proposal of new biostratigraphic units base don calcareous nannofossils for the Maastrichtian of the Santos Basin (Brazil). Anais da Academia Brasileira de Ciências, 69:37-58.

Ornellas L.P. 1981. Os ostracodes e seu significado na interpretação dos eventos cenozóicos na bacia de Pelotas, $R S$ : transgressões, regressões, paleoecologia e bioestratigrafia. Tese de Doutoramento, Instituto de Geociências, Universidade Federal do Rio Grande do Sul, 217 p.

Perch-Nielsen K. 1985. Cenozoic calcareous nannofossils. In: Bolli H.M., Saunders J.B, Perch-Nielsen K. (eds.) Plankton Stratigraphy. Cambridge University Press, Cambridge, p. 427-554.

Posamentier H.W. \& Vail P.R. 1988. Eustatic controls on clastic deposition II - sequence and systems tracts models. In: Wilgus C.K., Hastings B.S., Posamentier H.W., Van Wagoner J.C., Ross C.A., Kendall C.G. (eds.) Sealevel changes: an integrated approach, SEPM Special Publication, 42:125-154.

Premaor E., Fischer T.V., Arai M., Souza P.A. 2007. Palinologia da Bacia de Pelotas: Dados preliminares sobre a seção cretácica. In: SBP, Congresso Brasileiro de Paleontologia, 20, Anais, p. 231.

Regali M.S.P., Uesugui, N., Santos A.S. 1974. Palinologia dos Sedimentos Meso-Cenozóicos do Brasil (I). Boletim técnico da Petrobrás, 17(3):177-191.
Richards M., Bowman M., Reading H. 1998. Submarine-fan systems I: Charcaterization and stratigraphic prediction. Marine and Petroleum Geology, 15:689-717.

Rios-Netto, A.M. 1993. Caracterização bioestratigráfica do limite Oligoceno-Mioceno nas bacias marginais brasileiras. Anais da Academia Brasileira de Ciências, 65(4):407-411.

Rosa A.P. 2007. Interpretação sismo-estratigráfica da porção da Bacia de Pelotas que engloba o Cone do Rio Grande e a avaliação do seu potencial petrolífero. Tese de Doutorado, Instituto de Geociências, Universidade Estadual do Norte Fluminense, 252 p.

Sad A.R.E., Silveira D.P., Machado M.A., Silva S.R.P., Maciel R.R. 1998. Marine gas hydrates along the Brazilian coast. In: AAPG International conference and Exhibition. American Association of Petroleum Geologists Bulletin, 82(10):1423.

Sanguinetti Y.T. 1980. Bioestratigrafia (ostracodes) do Mioceno da Bacia de Pelotas, Rio Grande do Sul. Pesquisas, 13:7-34.

Shanmugam G. 1988, Origin, recognition and importance of erosional unconformities in sedimentary basins. In: Kleinspehn K.L. \& Paola C. (eds.) New perspectives in basin analysis. New York, Springer-Verlag, p. 83-108.

Shimabukuro S., Richter A.J., Gomide J. 1985. Nanofósseis calcários: bioestratigrafia do Mioceno ao Pleistoceno na plataforma continental brasileira. Departamento Nacional da Produção Mineral. Coletânea de Trabalhos Paleontológicos, 27(2):491-501.

Thiesen Z.V. 1977. Bolivinitidae e Caucasinidae (Foraminiferida) do Cenozóico superior da Bacia de Pelotas, Rio Grande do Sul. Acta Geológica Leopoldensia, 2(3):832.

Troelsen J.C. \& Quadros L.P. 1971. Distribuição bioestratigráfica dos nanofósseis marinhos (Aptiano/Mioceno) do Brasil. Anais da Academia Brasileira de Ciências, 43:577-609.

Veizer J., Buhl D., Diener A., Ebneth S., Podlaha O.G., Bruckshen P, Jasper T., Korte C., Schaaf M., Ala D., Azmy K. 1997. Stronium isotope stratigraphy: potential resolution and event correlation. Palaeogeography, Palaeoclimatology, Palaeoecology, 132:65-77.

Villwock J.A. \& Tomazelli L.J. 1995. Geologia costeira do Rio Grande do Sul. Notas Técnicas, 8:1-45.

Viviers M.C. \& Abreu W.S. 1995. Os macroforaminíferos nas bacias da margem equatorial brasileira: Uma contribuição a bioestratigrafia do Neogeno. Anais da Academia Brasileira de Ciências, 67(3):393.

\section{Manuscrito BR 19 \\ Submetido em 04 de janeiro de 2008 Aceito em 10 de abril de 2008}

